\title{
Innovative Medical Technology and the Treatment Decision-Making Process in Multiple Sclerosis: A Focus Group Study to Examine Patient Perspectives
}

\section{A Visser (D) \\ $M$ De Mul $\mathbb{D}^{2}$ \\ W K Redekop (D)}

'Health Technology Assessment, Erasmus School of Health Policy \& Management Erasmus University Rotterdam, Rotterdam, the Netherlands; ${ }^{2}$ Health Services Management \& Organization, Erasmus School of Health Policy \& Management, Erasmus University Rotterdam, Rotterdam, the Netherlands
Background: Disease-modifying therapies are given to people with multiple sclerosis (MS) to reduce disease progression and relapse frequency. Current modes of administration include oral, injectable and infusion therapy and the treatment decision-making process is complex. A novel mode of treatment administration, an implantable device, is currently under development, yet patient attitudes about the device are unknown. The aim of this study was 1) to understand the treatment decision-making process from the patient perspective and 2) to explore the possible acceptance of an implant to treat MS.

Methods: Focus groups with people with MS were conducted in the Netherlands. Three topics were addressed: the treatment decision-making process, the current treatment landscape, and attitudes about the implantable device. All focus groups were recorded and transcribed and data were analyzed by raw data coding and creating themes. An online survey was conducted in the Netherlands to quantify interest in an implant.

Results: Two focus group sessions were held ( $n=16$ participants) and $n=93$ persons filled out the survey. The main theme that emerged was the constant uncertainty persons with MS face throughout their disease course and during treatment decisions (when to start, stop, continue or switch treatment). Patients were generally positive towards the implant but felt that efficacy and safety should be guaranteed.

Conclusion: People with MS want some form of control over their disease and treatment course. New medical technologies, such as an implant, may enhance the treatment landscape and with caution we postulate that it may be accepted by patients as a new mode of administration, though further research is needed. For medical technologies to be successful, patients should be engaged early on in the design process.

Keywords: decision-making process, patient perspective, multiple sclerosis, medical technology

\section{Introduction}

Multiple sclerosis (MS) is a chronic degenerative disease of the central nervous system affecting 700,000 persons in Europe. ${ }^{1}$ Symptoms of MS include unilateral optic neuritis, asymmetrically reduced strength in the extremities and bowel and bladder dysfunction. MS is characterized by periods of neurological dysfunction, called a relapse, which the patient may partially or fully recover from, alternated with periods of remission. ${ }^{2}$
Health Technology Assessment, Erasmus School of Health Policy \& Management, Erasmus University Rotterdam, Bayle (J) Building, Room J8-15, Burgemeester Oudlaan 50, Rotterdam, 3062 PA, the Netherlands

Tel +3I 104088648

Email l.a.visser@eshpm.eur.nl 
Once diagnosed, people with MS can be treated with various disease modifying treatments (DMTs) to reduce the frequency of relapses and disease progression. DMTs differ in efficacy, safety and mode of administration. . $^{3,4}$ Treatments currently available on the market can either be taken at home, such as oral treatment and injections, or given in a hospital setting, such as infusion therapies. A new mode of administration is currently under development by the Optogenerapy consortium through a European Horizon 2020 funded project. Specifically, the consortium has been developing an optogenetics implant that will allow for the controlled release of beta interferon protein (INF $\beta$ ) delivery into the body. ${ }^{5,6}$ However, it is yet unknown whether people with MS feel the need for a new mode of administration and what drives their treatment decision-making process.

The aim of this study was two-fold: to understand the decision-making process in current MS care from a patient perspective and to explore the possible acceptance of implant therapy for MS.

\section{Materials and Methods}

Two separate qualitative and quantitative methods for data collection were used. Focus group sessions with people with MS were conducted to get a deeper understanding of the treatment decision-making process and acceptability of an implant. A focus group is a method in which less than 10 people converse with each other, and share views and opinions about the questions raised by the focus group researcher. ${ }^{7}$ The Consolidated Criteria for Reporting Qualitative research checklist was used to structure this manuscript. ${ }^{8}$

To quantify the possible acceptance of implant therapy, a European health-related quality of life (HRQOL) survey was performed between June and October 2019. The results and methodology are reported elsewhere. ${ }^{9}$ In addition to examining the HRQOL, patients were asked whether they would be interested in the Optogenerapy implant and to elaborate why, or why not, they would be interested (see Appendix 1). The results from the Dutch sample are included in the current paper.

\section{Patient Recruitment and Ethics}

The goal was to have a minimum of two focus groups with at least five persons with MS per group to achieve data saturation. Participants had to be older than 18 years of age, and no restrictions were made regarding type of MS and whether participants were currently using a DMT or not. We were primarily interested in the treatment decision-making process and therefore we did not exclude patients that were not eligible for INF $\beta$ treatment (such as patients with more severe $\mathrm{MS}^{10}$ ). Participants were given a gift card worth $€ 10$ as a mean of thanks for participating.

Participants were recruited by contacting local MS patient organizations in the Netherlands and emailing them with the question whether it was possible to give a brief presentation about the Optogenerapy project followed by a focus group session. Ten local MS patient organizations spread out over the Netherlands were contacted. The local organizations reached out to their members, and provided us with a list of interested members, which we checked for eligibility. Two organizations reacted positively to the request, two organizations declined participation and six locations did not respond to the email. Medical ethical approval was obtained for the focus groups by the Medical Research Ethics Committee of the Erasmus Medical Center (MEC-2019-0248). The study was conducted in accordance with the Declaration of Helsinki.

\section{Study Design}

The focus group sessions were held in September and October 2019. One researcher was present at each session (LV) and is trained in conducting interviews. Before the start of the focus group session, participants had to give written informed consent and their permission for the session to be audio recorded. Participants completed a short self-reported questionnaire on patient demographics at the start of the session (Appendix 2). A structured interview guide was followed (Appendix 3).

As the researcher had no prior relationships with the participants, the focus group session started with a 15minute introduction of the Optogenerapy project and implant (Appendix 4). ${ }^{5,6}$ The focus group itself consisted of an introduction, explaining the "rules" of the focus group, and three main topics: the treatment decisionmaking process, the current treatment landscape, and the Optogenerapy implant.

\section{Data Analysis}

Audio recordings and notes made during the meeting were fully transcribed. The transcripts of the focus groups were not returned to the participants for comments. Three authors (LV, MM, KR) independently used the systematic process of inductively coding the raw data and identifying statements to interpret the lived experience. This was followed by creating themes to cluster the meaning of 
the statement, and these themes were discussed until consensus was reached. Finally, the themes are described using textual descriptions. ${ }^{11}$ The qualitative data analysis was performed in Atlas.ti 8 software.

The open text fields of the online survey were translated to English by the first author (LV), and checked by a native speaker and co-author of this paper (WKR). The statements were coded thematically and grouped into topics, and these topics were discussed until consensus was reached.

\section{Results}

\section{Patient Demographics}

Two focus groups were held with a total of 16 participants (focus group $\mathrm{A}: \mathrm{n}=10$, focus group $\mathrm{B}: \mathrm{n}=6$ ). Both focus group sessions had a duration of 1 hour. They were held at a local community center where the members of the patient organization meet every month. All members with MS gave permission to participate in the focus group session; in both groups a spouse without MS was present during the session but did not participate in the discussion.

A total of 134 Dutch patients started the survey. Patients were dropped from the analysis if they did not complete the survey $(n=17)$, did not give informed consent $(n=13)$, did not live in the Netherlands $(n=9)$, and stated that their age of diagnosis was older than their current age $(n=2)$. This left 93 patients for analysis.

Patient demographics can be found in Table 1. The mean age of the participants of the focus group sessions was higher than the respondents in the survey (61 vs 44 years); their average age at diagnosis was also older (42 vs 35 years). The diagnosis and disability status were selfreported (and not verified by a neurologist). The majority of the patients were female (81\% and 70\%), had RRMS (56\% and $72 \%$ ), and were married (75\% and $47 \%)$. The majority of the focus group participants were currently not taking DMT (56\%); whereas half of the survey respondents were taking second-line DMT (50\%).

\section{Focus Group Sessions}

Three main themes (uncertainty vs control, the treatment decision-making process, and the implantable device) emerged from the analysis of the focus group sessions (contribution of codes to the finalized themes can be found in Table 2). Quotes are followed by indicating the gender (F: female, M: male) and age (in years) of the participant.

\section{Uncertainty vs Control}

The underlying theme across all phases of the disease and during the treatment decision-making process is uncertainty. Receiving the diagnosis "multiple sclerosis" may be perceived as a relief after a period of symptoms without any diagnosis. However, this results in the uncertainty associated with that diagnosis and not knowing what MS entails. Persons with MS are in the dark about how their disease will progress over time and the impact it will have on their lives.

I am still very much in the denial phase, I don't want it. In my head I can still do so much, while when actually doing something I quickly have to stop because I just can't do it anymore. So I am really still in that phase, yes: I still want to try. I still want to do so much. $(\mathrm{F}, 48)$

The uncertainty associated with the treatment decisionmaking process is evident during multiple phases of the disease course: at the start (concerns about if and when one should start taking a DMT), during the treatment course (concerns about the efficacy of the treatment), and when ceasing treatment (concerns about how the MS will progress without treatment). Furthermore, the treatment decision-making process is complicated because of the many DMTs available and having to choose the DMT that fits best into the life of the patient. All of these doubts and factors may have an impact on whether a person with MS is willing to start and continue with the treatment regimen.

It just gets you thinking, what are you doing? If you continue injecting and you do not know whether it will work or not. I just thought 'I will never know if I do not take it, or do take it, what the difference will be, because I just do not know how I do it by myself [without DMT]'. (F, 71)

The uncertainty makes the participants want to have some form of control over their disease. A large majority of the focus group participants, at some point during their disease course, opted to start taking one or more DMTs. By taking control over the disease some of the uncertainty is reduced thereby motivating the participants to continue therapy. As such, they show resilience against MS because they do not want to give in to the disease.

This month I started Natalizumab. Before that, I use Tecfidera, Copaxone and Fingolimod. All three didn't achieve the miracles that I had wished for. And now with Tysabri, I am hoping for a future with reduced disease progression. $(\mathrm{F}, 55)$ 
Table I Patient Demographics

\begin{tabular}{|c|c|c|}
\hline & $\begin{array}{l}\text { Total } \\
(n=16)\end{array}$ & $\begin{array}{l}\text { Online } \\
\text { Survey }(n=93)\end{array}$ \\
\hline Age, mean (range) & $61(48-82)$ & $44(23-70)$ \\
\hline Age at diagnose, mean (range) & $42(29-70)$ & $35(15-64)$ \\
\hline $\begin{array}{l}\text { Gender, } \mathrm{n}(\%)^{\mathrm{a}} \\
\text { Male } \\
\text { Female }\end{array}$ & $\begin{array}{l}3(19) \\
13(81)\end{array}$ & $\begin{array}{l}22(24) \\
70(75)\end{array}$ \\
\hline $\begin{array}{l}\text { MS Type } \\
\text { RRMS } \\
\text { PPMS } \\
\text { SPMS }\end{array}$ & $\begin{array}{l}9(56) \\
2(13) \\
4(25)\end{array}$ & $\begin{array}{l}72(77) \\
11(12) \\
9(10)\end{array}$ \\
\hline $\begin{array}{l}\text { Disease severity, } n(\%)^{c} \\
\text { Mild } \\
\text { Moderate } \\
\text { Severe } \\
\text { Unknown }\end{array}$ & $\begin{array}{l}\text { I }(6) \\
8(50) \\
4(25) \\
3(19)\end{array}$ & $\begin{array}{l}19(20) \\
20(22) \\
4(4) \\
33(18)\end{array}$ \\
\hline $\begin{array}{l}\text { Treatment, } \mathrm{n}(\%) \\
\text { Treatment naïve } \\
\text { Treatment experienced, but not } \\
\text { currently on DMT } \\
\text { On Ist line DMT } \\
\text { On 2nd line DMT }\end{array}$ & $\begin{array}{l}4(25) \\
9(56) \\
2(13) \\
1(6)\end{array}$ & $\begin{array}{l}10(11) \\
20(22) \\
17(18) \\
46(50)\end{array}$ \\
\hline $\begin{array}{l}\text { Marital status, n (\%) } \\
\text { Single } \\
\text { Partnered } \\
\text { Married } \\
\text { Divorced } \\
\text { Widowed }\end{array}$ & $\begin{array}{l}I(6) \\
12(75) \\
I(6) \\
2(13)\end{array}$ & $\begin{array}{l}19(20) \\
23(25) \\
44(47) \\
5(5) \\
2(2)\end{array}$ \\
\hline $\begin{array}{l}\text { Education, } \mathrm{n}(\%) \\
\text { Primary/secondary education } \\
\text { Vocational/technical education } \\
\text { University }\end{array}$ & $\begin{array}{l}7(44) \\
7(44) \\
2(13)\end{array}$ & $\begin{array}{l}10(11) \\
44(47) \\
39(42)\end{array}$ \\
\hline
\end{tabular}

Notes: ${ }^{a}$ The online survey also provided the answer category: prefer not to say $(n=I)$, 'The online survey also provided the answer category: clinically isolated syndrome $(n=1)$, ${ }^{c}$ The online survey had $n=17(18 \%)$ missing, ${ }^{d}$ In the focus groups the number of past disease-modifying therapies (DMT) used ranged from I-4. Abbreviations: MS, multiple sclerosis; PPMS, primary progressive multiple sclerosis; RRMS, relapsing-remitting multiple sclerosis; SPMS, secondary progressive multiple sclerosis.

\section{The Decision-Making Process}

When confronted with the diagnosis and being encouraged by a health care professional (HCP; physician or MS nurse) to start a DMT, patients feel overwhelmed and may choose not to start a DMT right away. The decision to start taking the DMT is made together with the HCP, whereas the choice to switch to another DMT or stop a DMT is made primarily by the patient or together with
Table 2 Codes Used for the Inductive Analysis to the Finalized Themes

\begin{tabular}{|c|c|}
\hline Theme & Contributing Codes \\
\hline $\begin{array}{l}\text { Uncertainty vs } \\
\text { control }\end{array}$ & $\begin{array}{l}\text { - Adverse events } \\
\text { - Body failing to cooperate } \\
\text { - Causes of MS unknown } \\
\text { - Efficacy of DMT unknown and the effect of } \\
\text { DMT on the body } \\
\text { - Frustration that new research and develop- } \\
\text { ment of DMTs is focussed on reducing dis- } \\
\text { - Une progression }\end{array}$ \\
\hline $\begin{array}{l}\text { The decision- } \\
\text { making process }\end{array}$ & $\begin{array}{l}\text { - Reasons for initiation of DMT (the need to } \\
\text { understand MS before starting treatment; } \\
\text { trade-offs regarding treatment choice: effi- } \\
\text { cacy, safety profile, mode of administration) } \\
\text { - Reasons for continuation of the DMT (hope; } \\
\text { at ease with current DMT) } \\
\text { - Reasons for discontinuation of the DMT } \\
\text { (adverse events; doubts about efficacy; dis- } \\
\text { ease progression) } \\
\text { - Shared decision-making with health care } \\
\text { practitioner }\end{array}$ \\
\hline $\begin{array}{l}\text { The implantable } \\
\text { device }\end{array}$ & $\begin{array}{l}\text { - Concerns about the implant (efficacy; safety } \\
\text { profile) } \\
\text { - Confrontation of being sick } \\
\text { - Reasons to opt for the implant (or not) }\end{array}$ \\
\hline
\end{tabular}

Abbreviations: DMT, disease-modifying therapy.

the HCP when DMT is no longer effective in preventing progression. During the shift from being unexperienced with the disease to being more experienced, the patient feels more empowered to make his/her own decisions.

When I had my first appointment with the neurologist, he told me how I should be treated. That was way too fast for me. I didn't even know what MS was. So I told him, I don't want it just yet. First I want to see what my own body does. I mean, it doesn't have be so aggressive. Because, how should I know? Two years later I did start [a DMT]. But then you know what MS is, and I did that for almost two years. But that I am not doing again either. (F, 71)

The choice of treatment is intertwined with the process of coming to terms with having MS. This is a complicating factor, because the trade-off has to be made between wanting to understand MS and coming to terms with the diagnosis before starting a DMT, or starting a DMT 
immediately but not knowing how the disease would progress without an intervention. Once diagnosed, the HCP encourages the use of a DMT as soon as possible. As such, the shared decision-making between HCP and patient is important, given the uncertainty the patient feels and the patient not knowing what DMT is best for him/herself. Therefore, the information given by the HCP should be clear regarding the efficacy and other aspects of the treatment.

When I got MS 4 years ago, the first year I didn't take anything until I had more spots after a relapse. They told me to go to the MS nurse, and there I was given a list with pros and cons and the side effects ... so then you choose something with the least side effects. Was that the right choice? I have had the disease for such a short period, so I can't say anything about the long-term. I mean, what is four years? Of which I have had Tecfidera for two. But hey, they [the HCP] can't say anything about the longterm effects either. $(F, 48)$

The choice for a DMT can be a rational and wellconsidered process based on weighing the importance of frequency and mode of administration, efficacy and safety. However, other participants mention that it was based on circumstantial information rather than such attributes.

The reason why I started injecting was because I thought, if the health insurance companies are willing to reimburse such an expensive drug, then it should be proven somewhere that it works. That was my only reason to start injecting. Even though I had heard only negative stories about it, actually. (M, 55)

A mechanism to cope with disease uncertainty is by taking a DMT. It is possible that participants with past treatment experience continue their current line of therapy because of their past experiences. Furthermore, past (negative) experiences (commonly due to side effects) made participants switch. Participants accept their current therapy and are willing to continue if they experience less or no side effects compared to past therapy. Nevertheless, participants are willing to accept a degree of side effects, or an inferior mode of administration, because they find it burdensome to switch again. Still, the core reason for continuing treatment is driven by the hope and fear that doing nothing will cause a more severe disease state.

I am afraid to stop [with DMT], because now things are going pretty well. I can walk a bit, I can do a bit of this and that. And if I stop and I have a relapse, I am just so very scared for that. $(\mathrm{F}, 48)$

The participants have vast experience with MS (time since diagnosis ranged from 3-51 years) which has allowed them to reflect on the uncertainty that comes with having MS. Doubts regarding the effect DMTs (may) have on the body and not knowing how one's body works with or without DMTs crossed their minds during the decision-making processes. Adverse events and disease progression enhance the concerns of whether the disadvantages of taking a treatment weigh against the potential health benefits. These apprehensions give them the courage to discontinue their treatment. Such a choice, and knowing that discontinuing may worsen their prognosis, shows that suffering from side effects may be worse than not knowing what the future may hold for them. Nevertheless, making that choice and accepting what may come regarding their disease progression is a difficult process to go through. Some participants, however, are reluctant to give up the hope of a "progression-free" future. Therefore, they may continue the treatment regime or switch to a more efficacious therapy. Notwithstanding, the need for new treatments that will cure rather than delay progression is great, and while the participants might have accepted MS to some degree, the underlying urge to conquer the disease remains.

I took Rebif for two years. At a certain moment in time it became so painful and the skin became hard. I told myself 'I am no longer going to hurt myself, I am quitting this stuff.' I stopped and thought 'whatever happens, happens but I am done with it'. (F, 71)

Why do they then have to continuously make more and more and more medications that reduce progression? If they had less side effects, then I would understand. But those side effects remain exactly the same. $(\mathrm{M}, 49)$

\section{The Implantable Device}

A new mode of administration such as the implantable device can be an enhancement to the current treatment landscape. However, the true need is a cure for MS and not a treatment with an efficacy and safety profile comparable to currently available treatments. Nevertheless, the participants were generally positive towards the implant. The implant has the ability to reduce the confrontation of being ill which can be experienced when having to inject treatment. However, not all modes of administration are 
seen as confrontational, such as taking a pill or a monthly visit to the hospital for infusion therapy.

I find injecting confrontational. A pill you can just take, as if it's a vitamin. When having MS you are already constantly confronted with it, and this [taking injections] creates even more confrontation. $(\mathrm{F}, 55)$

The implant is a mode of administration that can be given to patients at various stages in their disease course. Participants were willing to opt for the implant if they were suitable for it. However, given the long disease experience of most of the participants, they acknowledged that, in the light of the implant now being developed to release INF $\beta$, perhaps it would be best suited for patients with a mild disease course or relatively newly diagnosed. Nonetheless, some participants mentioned that, if they were eligible for the implant they would choose it. The implant is a way to improve the quality of life. Nevertheless, it has to suit one's preference, since one participant mentioned a fear of implantable devices in the body.

If you were given the choice between stopping the injections and starting with the implant, then I would choose the latter. I would say, fine, let's do it. Because you can just get up and go on. (F, 54)

I would choose it, even now, and in 10 years' time also. If I were eligible. (F, 62)

Given the yet unclear efficacy rates and side effect profile participants want certainty of those outcomes before starting such a mode of administration.

I would only allow it if you did not get sick from it. If you do not notice it ... But as long as such information cannot be given, I am going to wait until others have tried it. (M, 55)

In line with all the concerns raised during the decisionmaking process, patients want certainty on how this mode of administration can benefit them in the midst of the uncertainty that they already face daily.

\section{Online Survey Results}

Overall, three-quarters of the patients stated that they were (somewhat) interested in using the device (yes: $\mathrm{n}=19$ (20.4\%); maybe: $\mathrm{n}=49$ (52.7\%); no: $\mathrm{n}=25$ (26.9\%)). Amongst persons more recently diagnosed ( $\leq 6$ years; $\mathrm{n}=46 / 93$ (49\%), calculated by subtracting current age by age at diagnosis), most were somewhat interested in using the device (yes: $n=14 / 19$ (74\%); maybe: $n=29 / 49$ (59\%); no: $\mathrm{n}=3 / 25(12 \%))$. Most persons with 7 to 39 years since time of diagnosis $(n=47 / 93(51 \%))$ were not interested in the device. Some patients gave more than one reason why they would or would not be interested in the device.

Five main topics were identified that played a role in the interest in the device: the process of administering treatment, (no) need for the implant, efficacy-related reasons, side effects, and bodily integrity (Table 3). Most quotes were related to the process of administering treatment, such as the ease of use of the implant, and the effect on treatment adherence. The (lack of) need for the implant was driven by the current DMT taken by the survey respondents. The respondents mention that the efficacy of INF $\beta$ is insufficient, and that is a reason why they would not choose the implant. Also, more evidence regarding the implant results is needed before persons would choose the implant. The side effect profile of INF $\beta$ impacts the interest for the device as well. Respondents expect fewer side effects from the implant, but others also explicitly state that they would not choose the implant because of the known side effects of INF $\beta$. The respondents that would perhaps choose the implant are most concerned about their bodily integrity.

\section{Discussion}

This study aimed to understand the treatment decisionmaking process given the current treatment landscape, and to explore the possible acceptance of a new mode of administration, namely the Optogenerapy implant. The treatment decision-making process for persons with MS is a push-and-pull between uncertainty and the need for control. The uncertainty of living with MS may be somewhat reduced by controlling the disease via the use of a DMT. The Optogenerapy implant may possibly be a (medical technological) solution to reduce that uncertainty. Medical technology developers within the care of MS, and beyond, should be aware of these uncertainties and cater to these needs.

Patients face uncertainty in illness due to the complexity of the disease, its unpredictability and lack of information. ${ }^{12}$ Coping mechanisms may be used to deal with such issues. Participants of the focus group sessions mention that receiving the diagnosis of MS provided temporary relief because a label could be placed on their symptoms. However, reducing uncertainty through diagnosis is not the same as a cure, and patients may remain uncertain because of a greater awareness of the fragility of 
Table 3 Topics and Related Quotes That Play a Role in the Interest in the Optogenerapy Implant

\begin{tabular}{|c|c|c|}
\hline Topic & $\begin{array}{l}\text { Interest in } \\
\text { Device }\end{array}$ & Example Quotes \\
\hline \multirow[t]{3}{*}{$\begin{array}{l}\text { The process of administering } \\
\text { treatment }(n=30)\end{array}$} & Yes $(n=13)$ & $\begin{array}{l}\text { "Ease of use" } \\
\text { "I would not forget taking my medication" } \\
\text { "No more daily confrontation with MS" }\end{array}$ \\
\hline & $\begin{array}{l}\text { Maybe } \\
(n=16)\end{array}$ & $\begin{array}{l}\text { "Not easy to stop the treatment when experiencing side effects" } \\
\text { "I find it a bit scary" } \\
\text { "I think the implant can have positive effects on mental well-being" }\end{array}$ \\
\hline & No $(n=1)$ & "I feel like all the medications I have used for MS have only made the MS worse" \\
\hline \multirow[t]{3}{*}{ Need or no need $(n=25)$} & Yes $(n=5)$ & $\begin{array}{l}\text { "Good alternative to current medication because of difficulty injecting and swallowing" } \\
\text { "Would have chosen the device in the past (when still injecting), now switched to infusion } \\
\text { therapy" }\end{array}$ \\
\hline & $\begin{array}{l}\text { Maybe } \\
(n=11)\end{array}$ & $\begin{array}{l}\text { "I get the same results by smoking a joint" } \\
\text { "Currently I have a treatment that I don"t have to administer myself" }\end{array}$ \\
\hline & No $(n=9)$ & $\begin{array}{l}\text { "No current DMT use; however, interested if DMT use was needed" } \\
\text { "Enough implantable devices in the body already" }\end{array}$ \\
\hline \multicolumn{3}{|l|}{ Efficacy $(n=23)$} \\
\hline \multicolumn{3}{|c|}{ INF $\beta$ is not the correct DMT for the patients: } \\
\hline & Yes $(n=0)$ & \\
\hline & Maybe $(n=3)$ & $\begin{array}{l}\text { "I have primary progressive MS, INF } \beta \text { doesn"t work for me" } \\
\text { "INF } \beta \text { is not the right medication for me" }\end{array}$ \\
\hline & No $(n=7)$ & $\begin{array}{l}\text { "I am not against the implant, but the medication that is given" } \\
\text { "I have secondary progressive MS, INF } \beta \text { doesn"t work for me" }\end{array}$ \\
\hline \multicolumn{3}{|l|}{ Efficacy of INF $\beta$ is insufficient: } \\
\hline & Yes $(n=0)$ & \\
\hline & Maybe $(n=3)$ & $\begin{array}{l}\text { "It depends on the percentage of reducing the disease progression" } \\
\text { "I would consider it only if it has second-line treatment in it" }\end{array}$ \\
\hline & No $(n=4)$ & $\begin{array}{l}\text { "As long as inhibitors have not been conclusively proven to be effective, I don"t want anything" } \\
\text { "I would consider it if a second-line treatment was given in the device" }\end{array}$ \\
\hline \multicolumn{3}{|l|}{ Evidence is needed on efficacy: } \\
\hline & Yes $(n=0)$ & \\
\hline & Maybe $(n=6)$ & $\begin{array}{l}\text { "I want to see trial results first, but it sounds ideal" } \\
\text { "It depends on the experiences of other MS patients and what my neurologist can tell me about } \\
\text { it" }\end{array}$ \\
\hline & No $(n=0)$ & \\
\hline \multirow[t]{2}{*}{ Side effects $(n=19)$} & Yes $(n=7)$ & $\begin{array}{l}\text { "No skin lesions" } \\
\text { "I assume the implant releases the medication spread out over the day, and this differs from } \\
\text { taking a pill where the sudden overdoses gives me side effects" }\end{array}$ \\
\hline & Maybe $(n=6)$ & $\begin{array}{l}\text { "It depends on the side effects, in doubt because INF-B is known for its side effects" } \\
\text { "Perhaps with a better dosage the side effects will be less" }\end{array}$ \\
\hline
\end{tabular}

(Continued) 
Table 3 (Continued).

\begin{tabular}{|l|l|l|}
\hline Topic & $\begin{array}{l}\text { Interest in } \\
\text { Device }\end{array}$ & Example Quotes \\
\hline & No $(n=6)$ & $\begin{array}{l}\text { "I got sick from taking INF-B" } \\
\text { "My veins closed when a Port-A-Cath was inserted" }\end{array}$ \\
\hline \multirow{2}{*}{ Bodily integrity $(n=I)$} & Yes $(n=0)$ & \\
\cline { 2 - 3 } & Maybe $(n=9)$ & $\begin{array}{l}\text { "I don"t like it that my body will be cut open" } \\
\text { "No more control over when the treatment is administered" }\end{array}$ \\
\cline { 2 - 3 } & No $(n=2)$ & "I do not want a foreign object in my body" \\
\hline
\end{tabular}

Abbreviations: $\mathrm{N}$, the number of quotes found per topic; MS, multiple sclerosis.

their bodies. ${ }^{13-15}$ Any coping mechanisms that are used may differ depending on the stage of the disease, in which emotional-based coping develops into a more active and adaptive strategy over time. ${ }^{16}$ Patients may address this uncertainty by undergoing treatment at some point during their disease, as done by our participants and also found elsewhere. $^{14,17,18}$

Stakeholders involved in the development of medical technology should be aware that having an implantable device in one's body changes one's self-perception. Not only may technology affect one's social being, ${ }^{19}$ it shapes the experience of illness. ${ }^{20}$ Technology inserted into the body, such as neuromodulatory technology or implantable cardiovascular devices, changes how the body is viewed by a patient because the devices can affect and may take over certain processes within the body (for example spinal cord stimulation or cardiac rhythm). ${ }^{20-22}$ Thus, both the developers of a technology and patients receiving that technology have to understand that there is an intricate relationship between the body and technology which may affect the livability of the technology and how one accepts as part of their lives. ${ }^{21}$ Therefore, the extent to which patients accept and incorporate implantable devices into their daily lives is uncertain. Consequently, this type of information should be gathered, evaluated, and reevaluated continuously during the life cycle of a device to make sure the technology matches patient needs as well as possible.

Getting patients involved early in the device design and development has multiple benefits. Incorporating patients ensures that research is more likely to reflect the interest of the patient and improve the quality of the research by reflecting patient needs. ${ }^{23,24}$ Furthermore, there is a general agreement from the industry, regulatory authorities and health technology assessment bodies to involve patients and understanding their preferences early on during technology development. ${ }^{25-27}$ The design should not have a negative effect on their experience with the device. $^{21}$ So rather than a "technology-push" in which developers do not directly interact with the end user of a product, there should be a "demand pull" in which the technology should be designed to address the needs and preferences of the end user. ${ }^{28}$

Researchers need to study patient preferences in a systematic way to understand the needs and preferences of patients regarding treatment decisions and new medical technologies. One method to quantify such preferences are stated-preference techniques, such as discrete choice experiments (DCEs). A DCE asks patients to choose between two or more treatment choices (or profiles) based on a set of attributes and attribute levels. ${ }^{29}$ Previous studies have found that people with MS prefer treatments that delay disease progression, reduce relapses, and prefer oral and infusion modes of administration over injections. ${ }^{30,31}$ Furthermore, they have low preference for DMTs with a high treatment risk, such as significant adverse events. ${ }^{30}$ Our results indicate that the focus group participants and survey respondents would be interested in the device. Reasons include the avoidance of selfinjection, ease of use, and potentially less confrontation with being ill. However, they also indicated that since INF $\beta$ is the working substance of the implant, the implant is more appropriate for persons with recently diagnosed MS. Furthermore, concrete results of efficacy and safety profile are needed before participants would consider switching to the implant. Patient preferences of a new mode of administration such as an implant using the DCE methodology has not yet been done in MS. The results from the focus group sessions can inform 
researchers which patients to recruit and what attributes to include when examining preferences of modes of administration.

A method to incorporate patient preferences in device development is via co-design sessions. In co-design endusers are involved in the design process and work together with developers, thereby developing a device that is tailored to the needs of the end-users incorporating their personal experiences and know-how of a disease. ${ }^{32} \mathrm{Co}-$ design has been used in improving MS healthcare services, ${ }^{33,34}$ but not necessarily in product development, as seen in other disease areas. ${ }^{35-37}$ Design development is an iterative process and input from end-users should be incorporated at various moments during design development and see multiple prototypes. ${ }^{38,39}$ The results of our focus groups are informative and may be used as input to plan a co-design session. Furthermore, future research into co-design should follow a theoretical framework and may include various methods such as focus groups, brainstorm sessions, usability tests and interviews depending on the stage of development. ${ }^{39}$

The combined approach of the focus group study and online survey helped to understand the views of persons with MS regarding a novel mode of administration. It should be noted that the focus group participants attended only a short information session on the implantable device which may have been too short to enable a truly informed judgement. The online survey respondents were given a brief textual description of the survey, which may limit the interpretability of their open text answers. Furthermore, the focus group participants sometimes might have given socially desirable answers ("the implant is a way to improve quality of life") since the aims of the Optogenerapy consortium were shared. The views of 16 persons with MS are not enough to make representative conclusions for the whole MS community. However, we believe that combining the results with the survey provides valuable insights to use in further research and development. Follow-up steps could be stated preference methods and co-design sessions with patients and developers. These methods are not mutually exclusive and should instead be seen as complementary since they can add value to the design of a device.

This study has several limitations. Participants interested in attending the focus group sessions and learning more about the implant responded positively to the request, which could have resulted in selection bias.
Prior to the start of the focus group session the Optogenerapy implant was introduced, which may have led to pro-implant bias. However, we think that the bias is limited because the patients were not disproportionately enthusiastic about the device and viewed it from various perspectives. Furthermore, the implant was the last topic of the focus group session, which meant that some time had elapsed between the introductory talk and discussion about the implant.

Secondly, 56\% (9/16) of the focus group participants were currently no longer taking DMTs though had taken treatment in the past, which might have led to recall bias about what it was like to undergo treatment. However, the similarity between our study results and those found in previous MS focus groups studies ${ }^{14,18,40}$ suggest that the views expressed by the patients were valid.

Thirdly, the results of the focus group sessions were based on the views of 16 Dutch persons with MS living in the Netherlands, that are older than the general MS population. However, we observed similar views from the focus groups compared to the open text answers from the online survey, thus we believe that the results are somewhat generalizable for the Dutch MS population. Nonetheless, the results should be interpreted cautiously when making statements about persons with MS from other countries.

Fourthly, the focus group population was older than patients who may opt for an implant (ie younger, more recently diagnosed, and eligible for INF $\beta$ ). This was confirmed in the survey results (persons with shorter disease duration were more interested in the device). Therefore, it would be informative to have younger persons involved in future focus group or co-design sessions to compare their views to the results of this focus group study.

\section{Conclusion}

Uncertainty regarding disease and treatment course is ever present in the lives of persons with MS. Essentially, persons with MS want to have some form of control over their disease and treatment course. There is the potential for persons with MS to accept a new mode of administration, such as the implantable Optogenerapy device. However, patients will then have to accept letting go of the control and trusting that the device will do the work for them. New technologies within the field of MS, and healthcare in general, should be directed at the patients for whom this can potentially be life-changing and beneficial. More importantly, patients should be engaged early 
on in the design process and consistently thereafter to make sure that the device is tailored to their needs.

\section{Abbreviations}

DCE, discrete choice experiment; DMT, disease modifying treatment; HCP, health care professional; INF $\beta$, beta interferon; MS, multiple sclerosis; RRMS, relapsing-remitting multiple sclerosis; PPMS, primary progressive multiple sclerosis; SPMS, secondary progressive multiple sclerosis.

\section{Data Sharing Statement}

The data that support findings of this study are available on request from the corresponding author. The data are not publicly available due to privacy restrictions.

\section{Ethics Approval}

Trial registration number and date of registration: MEC2019-0248 (date of registration: 28/05/2019).

\section{Consent to Participate}

Written informed consent was obtained from all individual participants included in the study.

\section{Consent for Publication}

Patients signed informed consent regarding publishing their data.

\section{Acknowledgments}

Sincere thanks to all the focus group participants for their time and sharing their experiences.

\section{Author Contributions}

All authors made substantial contributions to conception and design, acquisition of data, or analysis and interpretation of data; took part in drafting the article or revising it critically for important intellectual content; agreed to submit to the current journal; gave final approval of the version to be published; and agree to be accountable for all aspects of the work.

\section{Funding}

European Union's Horizon 2020 research and innovation program under grant agreement no. 720694 . The funding sources had no involvement in the study design, the collection, analysis and interpretation of data, writing the report, or in the decision to submit the article for publication.

\section{Disclosure}

Dr W K Redekop report grants from European Union, during the conduct of the study. The authors report no other conflicts of interest in this work.

\section{References}

1. The European Multiple Sclerosis Platform. MS facts. MS Facts. Available from: http://www.emsp.org/about-ms/. Accessed April 29, 2021.

2. Brownlee WJ, Hardy TA, Fazekas F, Miller DH. Diagnosis of multiple sclerosis: progress and challenges. Lancet. 2017;389:1336-1346. doi:10.1016/S0140-6736(16)30959-X

3. Ingwersen J, Aktas O, Hartung HP. Advances in and algorithms for the treatment of relapsing-remitting multiple sclerosis. Neurotherapeutics. 2016;13:47-57. doi:10.1007/s13311-015-0412-4

4. Fogarty E, Schmitz S, Tubridy N, Walsh C, Barry M. Comparative efficacy of disease-modifying therapies for patients with relapsing remitting multiple sclerosis: systematic review and network meta-analysis. Mult Scler Relat Disord. 2016;9:23-30. doi:10.1016/ j.msard.2016.06.001

5. The Optogenerapy Consortium. Optogenerapy. Available from: https://optogenerapy.eu/about-optogenerapy/. Accessed April 29, 2021.

6. Michel F, Folcher M. Optogenerapy: when bio-electronic implant enters the modern syringe era. Porto Biomed J. 2017;2:145-149. doi:10.1016/j.pbj.2017.07.001

7. Tausch AP, Menold N. Methodological Aspects of Focus Groups in Health Research: results of qualitative interviews with Focus Group moderators. Glob Qual Nurs Res. 2016;3:2333393616630466.

8. Tong A, Sainsbury P, Craig J. Consolidated criteria for reporting qualitative research (COREQ): a 32-item checklist for interviews and focus groups. Int $J$ Qual Health Care. 2007;19:349-357. doi:10.1093/intqhe/mzm042

9. Visser LA, Louapre C, Uyl-de Groot CA, Redekop WK. Healthrelated quality of life of multiple sclerosis patients: a European multi-country study. Arch Public Health. 2021. doi:10.1186/s13690021-00561-z

10. Montalban X, Gold R, Thompson AJ, et al. ECTRIMS/EAN guideline on the pharmacological treatment of people with multiple sclerosis. Eur J Neurol. 2018;25(2):215-237. doi:10.1111/ene.13536

11. Creswell JW. Qualitative Inquiry and Research Design: Choosing Among Five Approaches. Sage; 2007; doi:10.1177/ 1524839915580941

12. Etkind SN, Koffman J. Approaches to managing uncertainty in people with life-limiting conditions: role of communication and palliative care. Postgr Med J. 2016;92(1089):412-417. doi:10.1136/ postgradmedj-2015-133371

13. Rogers WA, Walker MJ. Fragility, uncertainty, and healthcare. Theor Med Bioeth. 2016;37:71-83. doi:10.1007/s11017-016-9350-3

14. Mortensen GL, Rasmussen PV. The impact of quality of life on treatment preferences in multiple sclerosis patients. Patient Prefer Adherence. 2017;11:1789-1796. doi:10.2147/PPA.S142373

15. Irvine H, Davidson C, Hoy K, Lowe-Strong A. Psychosocial adjustment to multiple sclerosis: exploration of identity redefinition. Disabil Rehabil. 2009;31:599-606. doi:10.1080/09638280802243286

16. Keramat Kar M, Whitehead L, Smith CM. Characteristics and correlates of coping with multiple sclerosis: a systematic review. Disabil Rehabil. 2019;41:250-264. doi:10.1080/09638288.2017.1387295

17. Buesa-Estellez A, Cano-de-la-cuera R, Ortiz-Guiterrez RM, PalaciosCena D. The impact of pharmacological treatment on patients with multiple sclerosis. Disabil Health J. 2019;12:615-621. doi:10.1016/j. dhjo.2019.05.005 
18. Knaster ES, Yorkston KM, Johnson KL, McMullen KA, Ehde DM. Perspectives on self-management in multiple sclerosis: a focus group study. Int J MS Care. 2011;13:146-152. doi:10.7224/1537-2073-13.3.146

19. Mol A. Proving or improving: on health care research as a form of self-reflection. Qual Health Res. 2006;16:405-414. doi:10.1177/ 1049732305285856

20. Hofmann B, Svenaeus F. How medical technologies shape the experience of illness. Life Sci Soc Policy. 2018;14. doi:10.1186/s40504018-0069-y

21. Dalibert L. Living with spinal cord stimulation: doing embodiment and incorporation. Sci Technol Human Values. 2016;41:635-659. doi: $10.1177 / 0162243915617833$

22. Oudshoorn N. Sustaining cyborgs: sensing and tuning agencies of pacemakers and implantable cardioverter defibrillators. Soc Stud Sci. 2015;54:56-76. doi:10.1177/0306312714557377

23. van der Scheer L, Garcia E, van der Laan AL, van der Burg S, Boenink M. The benefits of patient involvement for translational research. Health Care Anal. 2017;25:225-241. doi:10.1007/s10728014-0289-0

24. Sacristán JA, Aguarón A, Avendaño-Solá C, et al. Patient involvement in clinical research: why, when, and how. Patient Prefer Adherence. 2016;10:631-640. doi:10.2147/PPA.S104259

25. MDIC. Medical Device Innovation Consortium (MDIC): Patient Centered Risk-Benefit Project Report. Medical Device Innovation Consortium (MDIC); 2015.

26. Whichello C, Bywall KS, Mauer J, et al. An overview of critical decision-points in the medical product lifecycle: where to include patient preference information in the decision-making process? Health Policy. 2020;124(12):1325-1332. doi:10.1016/j. healthpol.2020.07.007

27. Ho M, Saha A, McCleary KK, et al. A framework for incorporating patient preferences regarding benefits and risks into regulatory assessment of medical technologies. Value Health. 2016;19 (6):746-750. doi:10.1016/j.jval.2016.02.019

28. Shaw J, et al. Beyond "implementation": digital health innovation and service design. NPJ Digit Med. 2018:1-5. doi:10.1038/s41746018-0059-8

29. Webb EJD, Meads D, Eskyte I, et al. A Systematic review of discrete-choice experiments and conjoint analysis studies in people with multiple sclerosis. Patient. 2018;11(4):391-402. doi:10.1007/ s40271-017-0296-y

30. Reen GK, Silber E, Langdon DW. Multiple sclerosis patients' understanding and preferences for risks and benefits of disease-modifying drugs: a systematic review. J Neurol Sci. 2017;375:107-122. doi:10.1016/j.jns.2016.12.038
31. Visser LA, Louapre C, Uyl-de Groot CA, Redekop WK. Patient needs and preferences in relapsing-remitting multiple sclerosis: a systematic review. Mult Scler Relat Disord. 2020;39:101929. doi:10.1016/j.msard.2020.101929

32. Sanders EB-N, Stappers PJ. Co-creation and the new landscapes of design. Co-Design. 2008;4:5-18.

33. Thomson A, Rivas C, Giovannoni G. Multiple sclerosis outpatient future groups: improving the quality of participant interaction and ideation tools within service improvement activities. BMC Health Serv Res. 2015;15. doi:10.1186/s12913-015-0773-8

34. D’Young F, Samadi N, Boyd H, et al. Multiple sclerosis relapse recognition: using co-design to improve patient self-reports. $\mathrm{Br}$ J Neurosci Nurs. 2019;15(2):76-82. doi:10.12968/bjnn.2019.15.2.76

35. Eyles H, Jull A, Dobson R, et al. Co-design of mHealth delivered interventions: a systematic review to assess key methods and processes. Curr Nutr Rep. 2016;5(3):160-167. doi:10.1007/s13668016-0165-7

36. Graham T, Sooriah S, Giampieri S, Box R, Grocott P. Iterative codesign and testing of a novel dressing glove for epidermolysis bullosa. J Wound Care. 2019;28:5-14. doi:10.12968/ jowc.2019.28.1.5

37. Boyd H, Mckernon S, Mullin B, Old A. Improving healthcare through the use of co-design. N Z Med J. 2012;125(1357):76-87.

38. Page R. (2017). Speculative co-design: a framework for designing medical devices towards enhanced usability, through explorations of experience. In: Seemann K and Barron D, Editors. Design4Health, Melbourne. Proceedings of the Fourth International Conference on Design4Health 2017, (pp. page range of paper) Melbourne Cricket Ground, 4 - 7 Dec 2017, Melbourne, Victoria, Australia: Centre for Design Innovation, Swinburne University of Technology. ISBN-13: 978-0-6480892-1-6

39. Shah SGS, Robinson I, Alshawi S. Developing medical device technologies from users' perspectives: a theoretical framework for involving users in the development process. Int J Technol Assess Health Care. 2009;25:514-521. doi:10.1017/S0266462309990328

40. Lynd LD, Henrich NJ, Hategeka C, et al. Perspectives of patients with multiple sclerosis on drug treatment: a qualitative study. Int J MS Care. 2018;20(6):269-277. doi:10.7224/1537-2073.2017109
Patient Preference and Adherence

\section{Publish your work in this journal}

Patient Preference and Adherence is an international, peer-reviewed, open access journal that focusing on the growing importance of patient preference and adherence throughout the therapeutic continuum. Patient satisfaction, acceptability, quality of life, compliance, persistence and their role in developing new therapeutic modalities and compounds to optimize clinical outcomes for existing disease states are major areas of interest for the journal. This journal has been accepted for indexing on PubMed Central. The manuscript management system is completely online and includes a very quick and fair peer-review system, which is all easy to use. Visit http:// www.dovepress.com/testimonials.php to read real quotes from published authors. 